\title{
A morphometric study of the ulnar nerve in Guyon's canal
}

\author{
Müjde Uygur ${ }^{1}$, Gülgün Şengül ${ }^{2}$, Mete Ertürk ${ }^{2}$ \\ ${ }^{1}$ Department of Obstetrics and Gynaecology, Faculty of Medicine, Trakya University, Edirne, Turkey \\ ${ }^{2}$ Department of Anatomy, Faculty of Medicine, Ege University, Izmir, Turkey
}

\begin{abstract}
Objectives: Guyon's canal is clinically significant because it contains the ulnar nerve, artery and veins and is a location for compression injury. This study was undertaken to determine the anatomy of the ulnar nerve in Guyon's canal on 40 wrists of 20 adult formalin-fixed cadavers.

Methods: 40 wrists of 20 formalin-fixed adult cadavers obtained from the Department of Anatomy, Ege University Faculty of Medicine were dissected. In each cadaver, the skin and the subcutaneous fatty tissues were removed starting from the forearm down to the palm of the hand. The palmaris brevis muscle and the palmar aponeurosis were dissected to expose Guyon's canal.

Results: The length and diameter of the main trunk of the ulnar nerve in Guyon's canal before dividing into its terminal branches were measured as $11.72 \pm 1.99 \mathrm{~mm}$ and $3.41 \pm 0.5 \mathrm{~mm}$, consequently. Within the canal, the main trunk divided into two terminal branches. The diameter of the deep branch was $1.77 \pm 0.47 \mathrm{~mm}$ and the superficial branch was $2.41 \pm 0.45 \mathrm{~mm}$. The superficial branch divided into the proper palmar digital nerve supplying the medial side of the little finger and the common palmar digital nerve supplying the adjoining sides of little and ring fingers.

Conclusion: An accessory abductor digiti minimi muscle was observed as a possible cause of compression in Guyon's canal. Despite its clinical relevance, the diameters of the deep and superficial branches of the ulnar nerve in Guyon's canal do not exist in previous studies.
\end{abstract}

Keywords: morphometry; ulnar nerve; ulnar tunnel

Anatomy 2014;8:7-12, (c) 2014 TSACA

\section{Introduction}

Compression neuropathies of the ulnar nerve in the upper extremity are common. One of the sites of ulnar nerve compression is a fibroosseous tunnel at the wrist known as Guyon's canal (tunnel, lodge or space). Guyon's canal has also been termed canalis ulnaris ${ }^{[1]}$ the distal ulnar tunnel, ${ }^{[2]}$ carpal ulnar neurovascular space, ${ }^{[3]}$ pisoretinacular space, ${ }^{[4]}$ or the pisohamate tunnel. ${ }^{[5]}$ It was first described as a space at the base of the hypothenar eminence by the French surgeon Jean Casimir Felix Guyon in 1861 who became interested in a small protrusion on the palmar aspect of his wrist when he applied pressure to the hypothenar eminence. ${ }^{[6]}$ It was McFarlane who first described it as a tunnel shaped region between the pisohamate ligament and the fibrous arch of the hypothenar muscles. ${ }^{[5,7]}$

The palmar branch representing the continuation of the ulnar nerve passes through Guyon's canal and divides into superficial and deep terminal branches within the canal. The superficial terminal branch supplies the palmaris brevis muscle and the medial palmar skin. The deep terminal branch accompanies the deep branch of the ulnar artery as it passes between abductor digiti minimi and flexor digiti minimi brevis to follow the deep palmar arch dorsal to the flexor tendons. At its origin, the deep branch supplies three short muscles of the little finger. After leaving Guyon's canal, the superficial branch divides into two palmar digital nerves as the proper palmar digital nerve which supplies the medial side of the 
little finger and a common palmar digital nerve which sends a twig to the median nerves and divides into two proper digital nerves to supply the adjoining sides of little and ring fingers. ${ }^{[8]}$

Guyon's canal, 4-4.5 $\mathrm{mm}$ in length, includes the ulnar nerve, ulnar artery and veins, and loose fibroadipose tissue. Palmar carpal ligament, palmaris brevis muscle, hypothenar fat and fibrous tissue constitute the roof of the canal. ${ }^{[9]}$ The roof of Guyon's canal extends radially to the hook of hamate, allowing the ulnar artery and sensory component of the ulnar nerve to course radially to the hook of hamate, where they lie on the transverse carpal ligament (flexor retinaculum). ${ }^{[10]}$ The floor of Guyon's canal is composed of tendons of the flexor digitorum profundus and opponens digiti minimi muscles, the transverse carpal ligament, and the pisohamate and pisometacarpal ligaments. The flexor carpi ulnaris and abductor digiti minimi muscles and the pisiform bone form the medial wall. The lateral wall is composed of tendons of extrinsic flexors, the transverse carpal ligament and the hook of the hamate. ${ }^{[9]}$ The ulnar artery and veins are surrounded by fat in the proximal portion of Guyon's canal. In the distal portion at the level of the hamulus, Guyon's canal bifurcates into two separate channels: the continuation of the main ulnar tunnel containing the superficial ulnar nerve and artery, and a deep tunnel containing the deep motor branch of the ulnar nerve. At the distal edge of the hamulus, a fascial line or a thin muscle band separates the superficial from the deep canal. This represents the fibrous arch of the flexor digiti minimi brevis muscle, or the muscle body itself attaching to the hamulus. ${ }^{[1]}$ The roof and radial border of the Guyon's canal are divided into three segments: a proximal segment extending from the pisiform to the level of the hook of hamate, a central segment containing only adipose tissue and a distal fascial layer including the palmaris brevis muscle. ${ }^{[10]}$

Despite the clinical relevance of ulnar nerve in Guyon's canal, few anatomic studies give detailed information on the morphometry of the ulnar nerve and its superficial and deep branches here. This study was undertaken to determine the anatomy of the branches of ulnar nerve in Guyon's canal on a large series of cadaver specimens to be a reference for hand surgeons during wrist surgery.

\section{Materials and Methods}

In this study, 40 wrists of 20 formalin-fixed adult cadavers (age ranging from 50 to 65 years; 19 male, 1 female) obtained from the Department of Anatomy, Ege University Faculty of Medicine were dissected. In each cadaver, the skin and the subcutaneous fatty tissues were removed starting from the forearm down to the palm of the hand. The palmaris brevis muscle and the palmar aponeurosis were dissected to expose Guyon's canal. The ulnar nerve and artery were observed. The length of the main trunk of the ulnar nerve in Guyon's canal was measured as the distance from the proximal border of the pisiform bone to the ulnar nerve bifurcation. The diameters of the main trunk, the deep branch and the superficial branch and its terminal branches were measured using a surgical magnifying glass with a 2.5 fold magnification. As the cross-section of the ulnar nerve and its branches were round to oval in shape, the measurements were made along the largest diameter. All measurements were made with a digital stainless steel caliper (Anhui Measuring Tools Company, Anhui, China) with $0.1 \mathrm{~mm}$ accuracy. Mean and Standard deviation (SD) values were calculated for each parameter. The parameters measured were normally distributed, therefore paired samples ttest was used for statistical analysis for the assessment of right-left differences.

The relationship of the ulnar nerve and its branches with the transverse carpal ligament and the ulnar artery were investigated. Also, the presence of anomalous muscles within Guyon's canal as a possible cause for ulnar nerve compression was explored.

\section{Results}

The ulnar nerve gave the dorsal branch of the ulnar nerve from its medial aspect at a distance of $6.4 \pm 2.3 \mathrm{~mm}$ from the wrist. After that, the ulnar nerve ran superficially to the transverse carpal ligament and entered Guyon's canal. In Guyon's canal, the ulnar nerve ran dorsal to the palmar carpal and palmar to the transverse carpal ligaments and flexor digitorum tendons. It divided into two terminal branches as the superficial and deep branches. In all cases, ulnar artery and veins ran superficial and radial to the superficial branch of the ulnar nerve within Guyon's canal (Figure 1).

The length of the main trunk of the ulnar nerve in Guyon's canal before dividing into terminal branches was $11.72 \pm 1.99 \mathrm{~mm}$. The diameter of the main trunk, deep branch, the superficial branch and its terminal branches are shown in Table 1. The length values measured were normally distributed, and paired samples t-test was used for statistical analysis for the assessment of right-left differences. The diameter values measured were normally distributed, and paired samples t-test was used for statistical analysis for the assessment of rightleft differences. No statistically significant right-left differences were observed for any of these parameters 


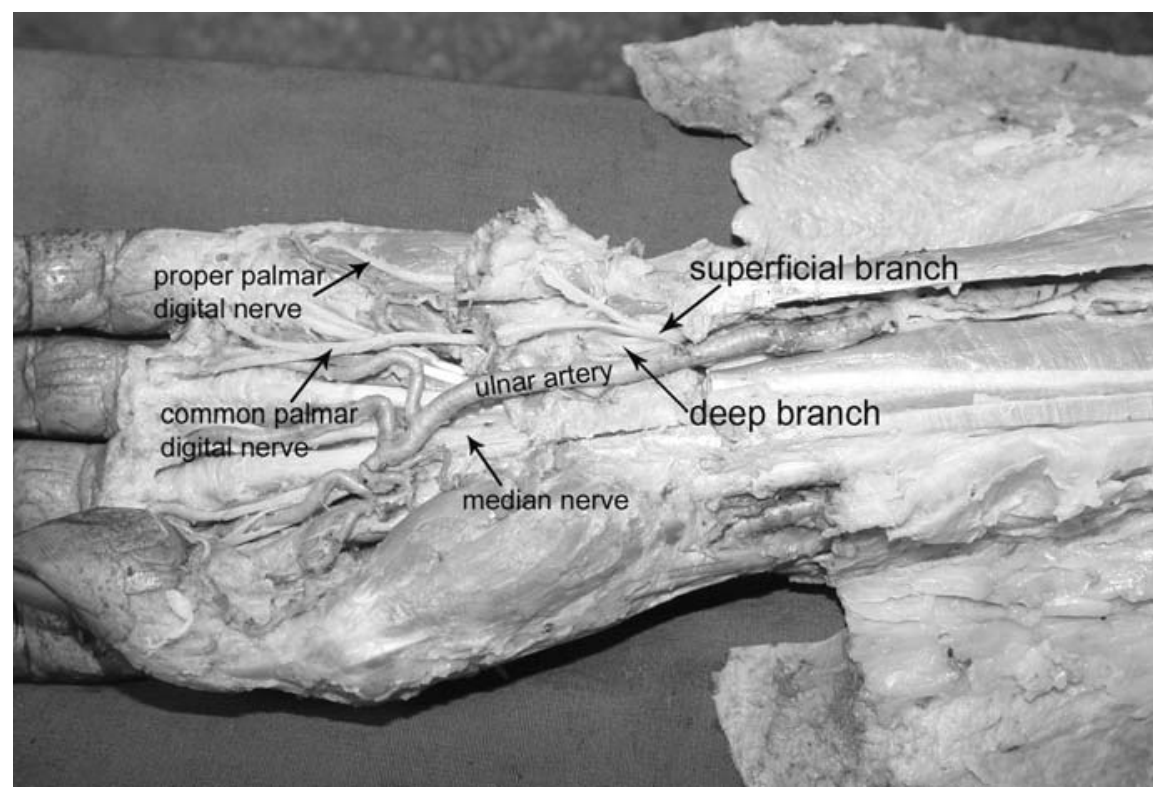

Figure 1. Ulnar nerve in Guyon's canal.

except for the diameter of the proper palmar digital nerve being significantly larger on the left side $(\mathrm{p}=0.03)$

A unilateral accessory abductor digiti minimi muscle was discovered on the left side of a male cadaver originating from the deep antebrachial fascia and running obliquely down on to the Guyon's canal, as a possible cause of compression in Guyon's canal, creating a fibrous arch over the nerve. It terminated fusing with the fibers of the abductor digiti minimi muscle. The muscle was located on the anterior aspect of the forearm superficial to flexor digitorum superficialis muscle (Figure 2, Figure 3). Its spindle shaped belly was approximately 12 $\mathrm{cm}$ long and $2 \mathrm{~cm}$ wide.

\section{Discussion}

The most common causes of ulnar tunnel syndrome (ulnar nerve compression) in Guyon's canal are occupa- tional traumatic neuritis, ganglion cyst, tumor, thrombosis of ulnar artery, fractures of the pisiform or hook of hamate, rheumatoid arthritis synovitis, a musculotendinous arch and nerve anomalies. ${ }^{[12-14]}$ In addition to these, a rare cause of compression is anatomic variations of muscles in Guyon's canal. These variations are reported as anomalous palmarislongus, ${ }^{[15,16]}$ flexor digiti minimi brevis ${ }^{[17,18]}$ or abductor digiti minimi muscle $e^{[14,15,17,19-23]}$ a variantabductor-flexor muscle of the little finger, ${ }^{[2]}$ accessory flexor profundus ${ }^{[25]}$ or flexor carpi ulnaris ${ }^{[15,26]}$ muscles coursing through the canal. ${ }^{[27,28]}$ In this study, an accessory abductor digiti minimi muscle was observed as a possible cause of compression in Guyon's canal, creating a fibrous arch over the nerve.

Ulnar nerve compression may cause weakness and atrophy of intrinsic hand muscles and loss of sensation in the ulnar nerve distribution of the hand. Posner described

Table 1

The diameters of the main trunk, deep branch and the superficial branch and its terminal branches (proper palmar digital nerve and common palmar digital nerve) of the ulnar nerve (paired samples t-test).

\begin{tabular}{lccc}
\hline \multirow{2}{*}{ Nerve } & \multicolumn{3}{c}{ Diameter } \\
\cline { 2 - 4 } & Right & Left & Total \\
\hline Main trunk & $3.34 \pm 0.47$ & $3.48 \pm 0.54$ & $3.41 \pm 0.5$ (min. 2.4-max. 4.18) \\
Deep branch & $1.73 \pm 0.47$ & $1.82 \pm 0.49$ & $1.77 \pm 0.47$ (min. 0.64-max. 2.53) \\
Superficial branch & $2.28 \pm 0.37$ & $2.63 \pm 0.69$ & $2.41 \pm 0.45$ (min. 1.52-max. 3.45) \\
Proper palmar digital nerve & $1.45 \pm 0.25$ & $1.67 \pm 0.35 *$ & $1.73 \pm 0.31$ (min. 1.11-max. 2.32) \\
Common palmar digital nerve & $1.69 \pm 0.32$ & $1.76 \pm 0.32$ & $1.53 \pm 0.25$ (min. 1.03-max. 2) \\
\hline
\end{tabular}

Values are mean \pm standard deviation (range), $\mathrm{mm} .{ }^{*}: p<0.05$ 
Figure 2. Ulnar nerve, abductor digiti minimi and the accessory abductor digiti minimi (arrowhead) muscles.

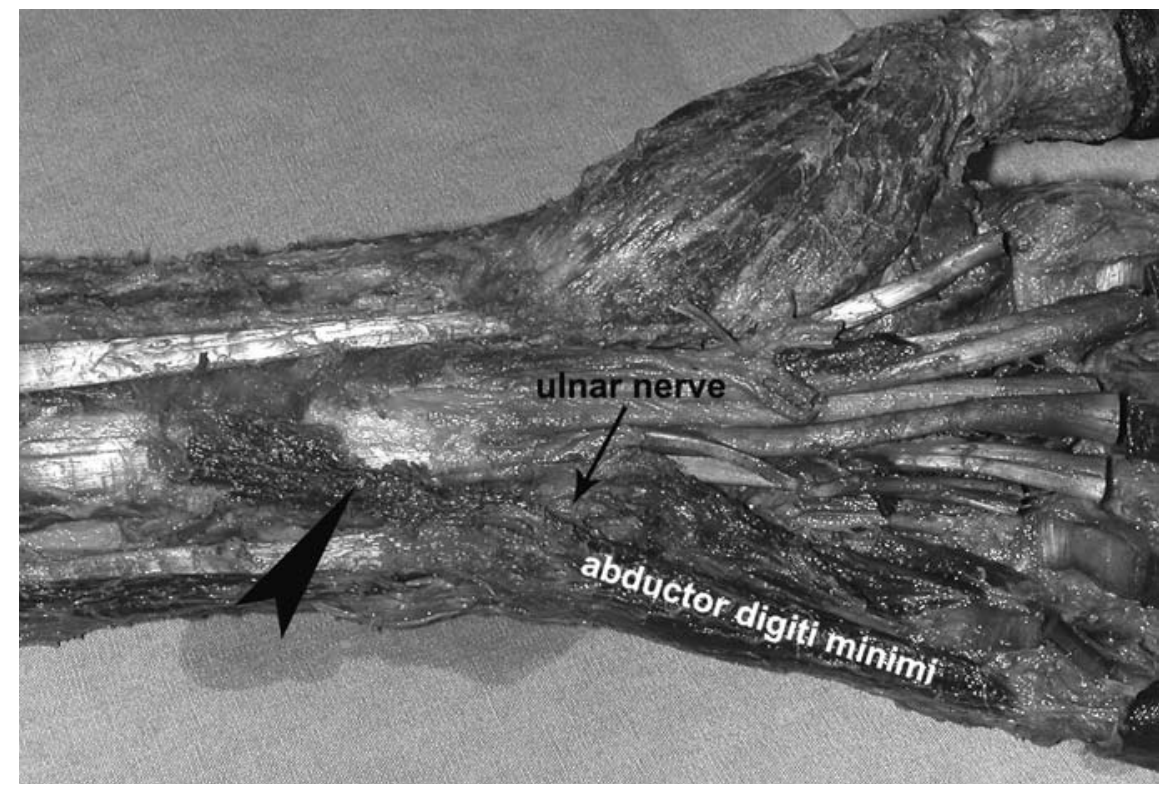

Zone 1 as the most proximal portion of the canal where the nerve is a single structure consisting of motor and sensory fascicles, and zones 2 and 3 are distal where the ulnar nerve has divided into motor and sensory branches. ${ }^{[2]]}$ The symptoms of ulnar nerve compression correlate with the zone in which compression occurs. Grundberg defined ulnar nerve compression at the wrist as of two distinct types. ${ }^{[30]}$ In the first type, compression is at the level of the pisiform with the involvement of both sensory and motor fibers. In the second type, compression is distal to the pisiform with the involvement of the motor fibers only.
Surgical release of the ulnar nerve at the wrist involves deroofingGuyon's canal. During surgical exposure of Guyon's canal, there is risk of damaging neurovascular structures close to the transverse carpal ligament such as the ulnar nerve trunk or its branches and the ulnar artery. Arthroscopic wrist surgery is also commonly used to treat a number of conditions of the wrist including chronic wrist pain, wrist fractures, ganglion cysts, ligament tears, and tears of the triangular fibrocartilage complex. During arthroscopic surgery, an accidental entry into Guyon's canal may result with ulnar nerve

Figure 3. Relationship between the accessory abductor digiti minimi muscle (arrowhead) and the ulnar nerve.

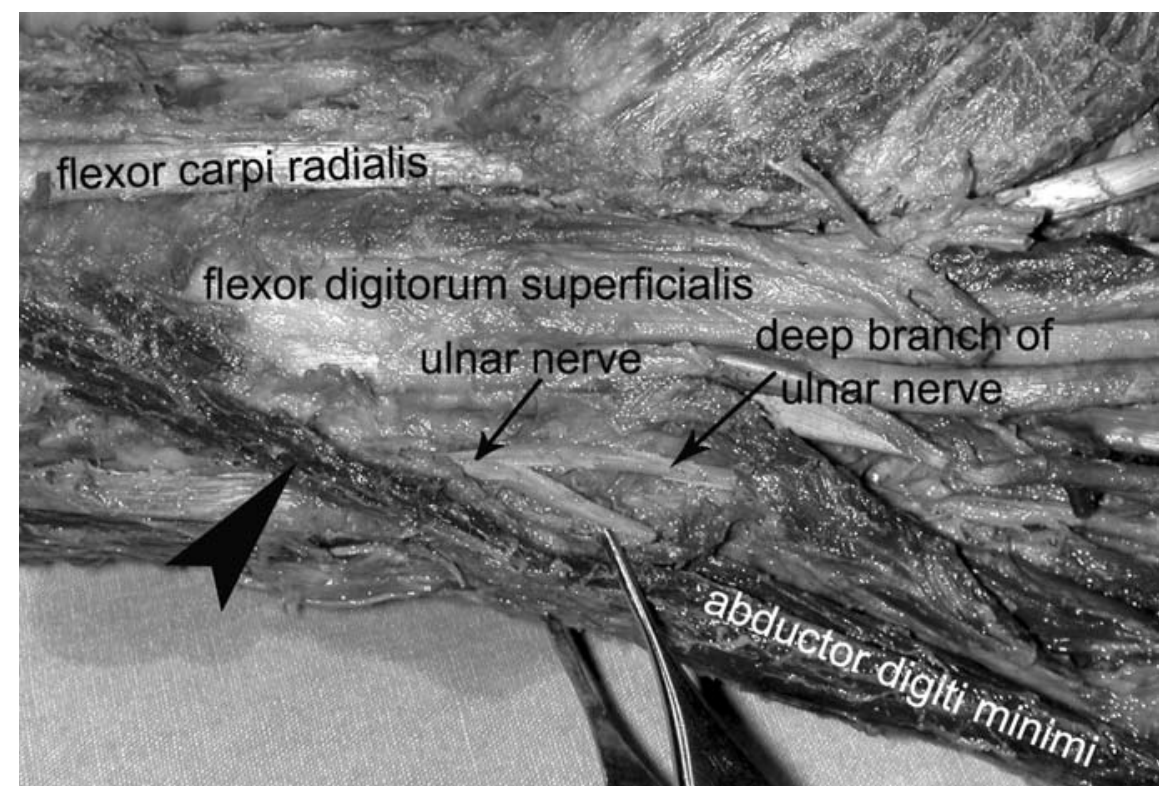


injury. Radiography, multidetector computed tomography (CT), multidetector CT arthrography, and magnetic resonance imaging (MRI) of the wrist are useful for surveying the anatomy of Guyon's canal. ${ }^{[31]}$

Despite the clinical relevance of Guyon's canal, morphometric studies on the ulnar nerve here are very rare. Murata et al., ${ }^{[32]}$ in a cadaveric study on 35 specimens, observed the ulnar nerve bifurcating into a deep branch and a superficial branch just distal to the distal edge of the pisiform. Zeiss et al. examined the normal anatomy of the Guyon's canal using MRI. ${ }^{[1]]}$ In their study, the ulnar nerve was round or oval with a mean diameter of $3 \pm 1 \mathrm{~mm}$, and the length of the main trunk was $11.6 \pm 2.5 \mathrm{~mm}$. Gross and Gelberman measured the length of the main trunk as 11 $\mathrm{mm} .{ }^{[9]}$ At the proximal end of the canal, the shape was generally triangular, with the base of the triangle directed towards the pisiform bone. The average transverse width of the canal was $11 \pm 5 \mathrm{~mm}$, and its greatest anteroposterior depth was $7 \pm 4 \mathrm{~mm}$. At the middle of the canal, the shape was either triangular or oval. The greatest transverse and anteroposterior dimensions of the canal were $13 \pm 5 \mathrm{~mm}$ and $6 \pm 4 \mathrm{~mm}$, respectively. The general configuration of the superficial tunnel was biconvex or discoid $14 \pm 6 \mathrm{~mm}$ wide and $5.5 \pm 2 \mathrm{~mm}$ deep at the distal portion of the Guyon's canal. Peeters et al. measured the ulnar nerve and its branches in Guyon's canal in an ultrasonographic study. ${ }^{[33]}$ They measured the anteroposterior diameter of the main trunk as $2.5(2.3-2.7) \mathrm{mm}$ on the right and 2.6 (2.4-2.9) $\mathrm{mm}$ on the left side. The transverse diameter was measured as $3.8(3.3-4.3) \mathrm{mm}$ on the right and $3.7(3.3-4.1)$ $\mathrm{mm}$ on the left. They observed no significant differences between left- and right-side measurements. The results of these MR and ultrasound studies are consistent with this anatomical study on cadavers, indicating our measurements are relevant in clinical cases. In addition to former studies, this study presents diameters of the two terminal branches of the superficial branch of the ulnar nerve in Guyon's canal.

Despite the clinical relevance of the ulnar nerve and its branches within Guyon's canal, few morphometric details have been described in the literature and the diameter of its superficial and deep branches have not been measured. An understanding of the contents of Guyon's canal, their positions and morphometry allows the surgeon to perform a correct approach and accurately identify structures during procedures at or near the Guyon's canal. This morphometric study was designed to help hand surgeons in reducing damage to neurovascular structures of Guyon's canal in order to avoid complications and to ensure optimal patient outcome during wrist surgery.

\section{References}

1. Eckman PB, Perlstein G, Altrocchi PH. Ulnar neuropathy in bicycle riders. Arch Neurol 1975;32:130-2.

2. Forshell KP, Hagström P. Distal ulnar nerve compression caused by ganglion formation in the loge de Guyon. Case report. Scand J Plast Reconstr Surg 1975;9:77-9.

3. Cobb TK, Carmichael SW, Cooney WP. The ulnar neurovascular bundle at the wrist. A technical note on endoscopic carpal tunnel release. J Hand Surg Br 1994;19:24-6.

4. Denman EE. The anatomy of the space of Guyon. Hand 1978;10: 69-76.

5. McFarlane RM, Mayer JR, Hugill JV. Further observations on the anatomy of the ulnar nerve at the wrist. Hand 1976;8:115-7.

6. Guyon F. Note sur une disposition anatomique propre à la face antérieure de la région du poignet et non encour décrite par le docteur. Bull Soc Anat Paris 1861;6:184-6.

7. Grantham SA. Ulnar compression in the loge de Guyon. JAMA 1966;197:509-10.

8. Johnson D, Ellis H. Pectoral girdle and upper limb. In: Standring S, ed. Gray's Anatomy. 39th ed. London: Churchill Livingstone; 2005. p. 932.

9. Gross MS, Gelberman RH. The anatomy of the distal ulnar tunnel. Clin Orthop Relat Res 1985;196:238-47.

10. Cobb TK, Carmichael SW, Cooney WP. Guyon's canal revisited: an anatomic study of the carpal ulnar neurovascular space. J Hand Surg Am 1996;21:861-9.

11. Zeiss J, Jakab E, Khimji T, Imbriglia J. The ulnar tunnel at the wrist (Guyon's canal): normal MR anatomy and variants. AJR Am J Roentgenol 1992;158:1081-5.

12. Aguiar PH, Bor-Seng-Shu E, Gomes-Pinto F, et al. Surgical management of Guyon's canal syndrome, an ulnar nerve entrapment at the wrist: report of two cases. ArqNeuropsiquiatr 2001;59:106-11.

13. Haferkamp H. Ulnar nerve compression in the area of the wrist. Langenbecks Arch Chir Suppl Kongressbd 1998;115:635-40.

14. Spiess AM, Gursel E. Entrapment of the ulnar nerve at Guyon's canal by an accessory abductor digiti minimi muscle. Plast Reconstr Surg 2006;117:1060-1.

15. De Smet L. Median and ulnar nerve compression at the wrist caused by anomalous muscles. Acta Orthop Belg 2002;68:431-8.

16. Santoro TD, Matloub HS, Gosain AK. Ulnar nerve compression by an anomalous muscle following carpal tunnel release: a case report. J Hand Surg Am 2000;25:740-4.

17. Bozkurt MC, Tağil SM, Ozçakar L, Ersoy M, Tekdemir I. Anatomical variations as potential risk factors for ulnar tunnel syndrome: a cadaveric study. Clin Anat 2005;8:274-80.

18. Madhavi C, Holla SJ. Anomalous flexor digiti minimi brevis in Guyon's canal. Clin Anat 2003;16:340-3.

19. Al-Qattan MM. Ulnar nerve compression at the wrist by the accessory abductor digiti minimi muscle: wrist trauma as a precipitating factor. Hand Surg 2004;9:79-82.

20. Curry B, Kuz J. A new variation of abductor digiti minimi accessorius. J Hand Surg Am 2000;25:585-7.

21. Harvie P, Patel N, Ostlere SJ. Ulnar nerve compression at Guyon's canal by an anomalous abductor digiti minimi muscle: the role of ultrasound in clinical diagnosis. Hand Surg 2003;8:271-5.

22. Netscher D, Cohen V. Ulnar nerve compression at the wrist secondary to anomalous muscles: a patient with a variant of abductor digiti minimi. Ann Plast Surg 1997;39:647-51. 
24. Georgiev GP, Jelev L, Surchev L. Undescribed variant muscle-"deep abductor-flexor" of the little finger, in relation to ulnar nerve compression at the wrist. Ann Anat 2007;189:276-82.

25. Wahba MY, Singh GD, Lozanoff S. An anomalous accessory flexor digiti minimi profundus muscle: a case study. Clin Anat 1998; 11:55-9.

26. Hill ML, Shoja MM, Salter EG, Tubbs RS. An unusual muscle of the wrist with potential compression of the ulnar nerve. Folia Morphol (Warsz) 2006;65:178-80.

27. Dodds GA 3rd, Hale D, Jackson WT. Incidence of anatomic variants in Guyon's canal. J Hand Surg Am 1990;15:352-5.

28. Harvie P, Patel N, Ostlere SJ. Prevalence and epidemiological variation of anomalous muscles at guyon's canal. J Hand Surg Br 2004:29:26-9.
29. Posner MA. Compressive neuropathies of the ulnar nerve at the elbow and wrist. Instr Course Lect 2000;49:305-17.

30. Grundberg AB. Ulnar tunnel syndrome. J Hand Surg Br 1984;9: $72-4$.

31. Blum AG, Zabel JP, Kohlmann R, et al. Pathologic conditions of the hypothenar eminence: evaluation with multidetector CT and MR imaging. Radiographics 2006;26:1021-44.

32. Murata K, Tamai M, Gupta A. Anatomic study of variations of hypothenar muscles and arborization patterns of the ulnar nerve in the hand. J Hand Surg Am 2004;29:500-9.

33. Peeters EY, Nieboer KH, Osteaux MM. Sonography of the normal ulnar nerve at Guyon's canal and of the common peroneal nerve dorsal to the fibular head. J Clin Ultrasound 2004;32:37580 .

\section{Correspondence to: Mete Ertürk, MD}

Department of Anatomy, Faculty of Medicine,

Ege University, Bornova, 35100, Izmir, Turkey

Phone: +902323903985

e-mail: mete.erturk@ege.edu.tr

Conflict of interest statement: No conflicts declared. 